\title{
Considerations of a Swiss Monument Preservationist during a Visit to Traditional Villages in China: The Yunnan Shaxi Rehabilitation Project as an Opportunity
}

\author{
Christian Renfer \\ Swiss Federal Department of Culture, Zurich, Switzerland
}

\begin{abstract}
The article elaborates the thoughts and recommendations from a Swiss monument preservationist view point towards the issues and developments of rural cultural landscapes in China, with case studies on the joint Swiss-Chinese Rehabilitation Project of Shaxi, and the traditional villages in the provinces of Guizhou and Guangxi.
\end{abstract}

KEYWORDS Shaxi Rehabilitation Project, cultural landscape preservation, spatial planning, Chinese village

\section{My First Contact with Monument Preservation in China}

In the year 2002 I had the opportunity to visit China for the first time, as part of a delegation from the city of $\mathrm{Zu}$ rich, and was able to take part in discussions with monument preservation experts from the city of Kunming. At that time there was already a long standing concept for retaining the old city and a monument preservation position had been created in the planning department.

I visited the city four years later, in October 2006, for the last time. To my surprise, most areas of the old city had already been destroyed except for the Muslim quarter, where I was able to take the last pictures of its destruction (Figure 1). I don't know the background of this change, therefore I also cannot judge the course of events. Clearly here development and preservation concept were diametrically opposed, so that planning which could have brought about a building synthesis between the old city of Kunming together with the developing areas was no longer possible. The reality of the city development in Kunming was a real culture shock for me as an experienced preservationist.

\section{A New Experience with Monument Preservation in China: the Shaxi Rehabilitation Project (2000-2006)}

If the view of Kunming had been my only experience with monument preservation in China, I would have had a completely wrong picture of the possibilities in this country. Happily I was allowed to take part in a joint SwissChinese project in the province of Yunnan, in which completely different perspectives of monument preservation were put into practice. After completion of planning, the results of this project, which was conceptually an especially successful one, have become visible since 2006 in a first and second realisation phase (2001-2006). Today we can assess the results of 11 years of implementation. I would like to transmit to you some basic thoughts and illustrate them with some pictures.

\section{A Synopsis of the Shaxi Rehabilitation Project}

Preliminary Remarks - from Switzerland to China

The Shaxi Project is somewhat of a role model for China in that there are similar rural cultural landscapes with intact villages and traditional structure in other parts of China which would be of value to retain as complete units and to develop further. It is particularly the still intact areas of national minorities which demonstrate, on the basis of an enormous backlog, a high rate of destruction in their traditional communities. This destruction is not only visible because of large buildings but also in all of the small additions to the buildings or dwellings, perpetrated without any consideration in the communities. As a large country in which agriculture, different from European countries, still has an important place in the economy, it is worthwhile to develop regional development with 


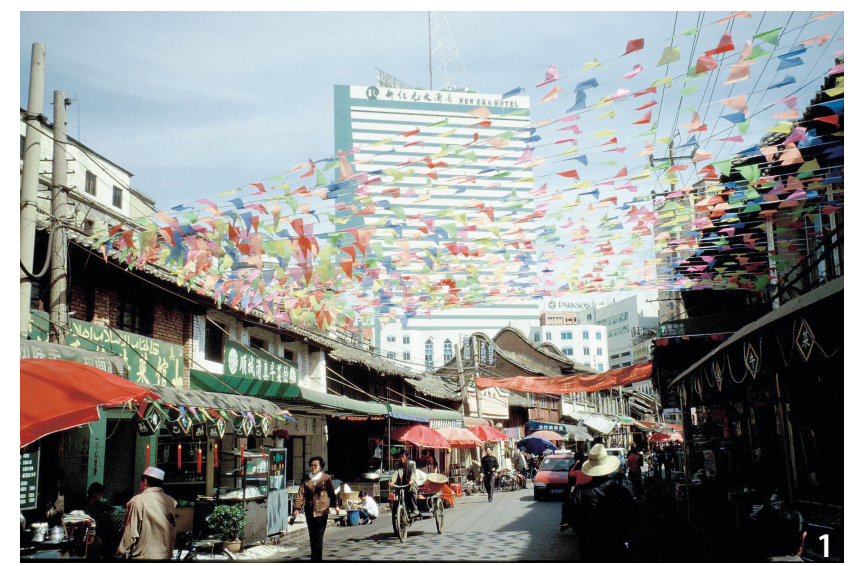

Figure 1 The Muslim quarter in Kunming (Source: the author). Figure 2 Longcheng Village in Guangxi Province (Source: the author). Figure 3 Lumnezia in Switzerland (Source: the author).
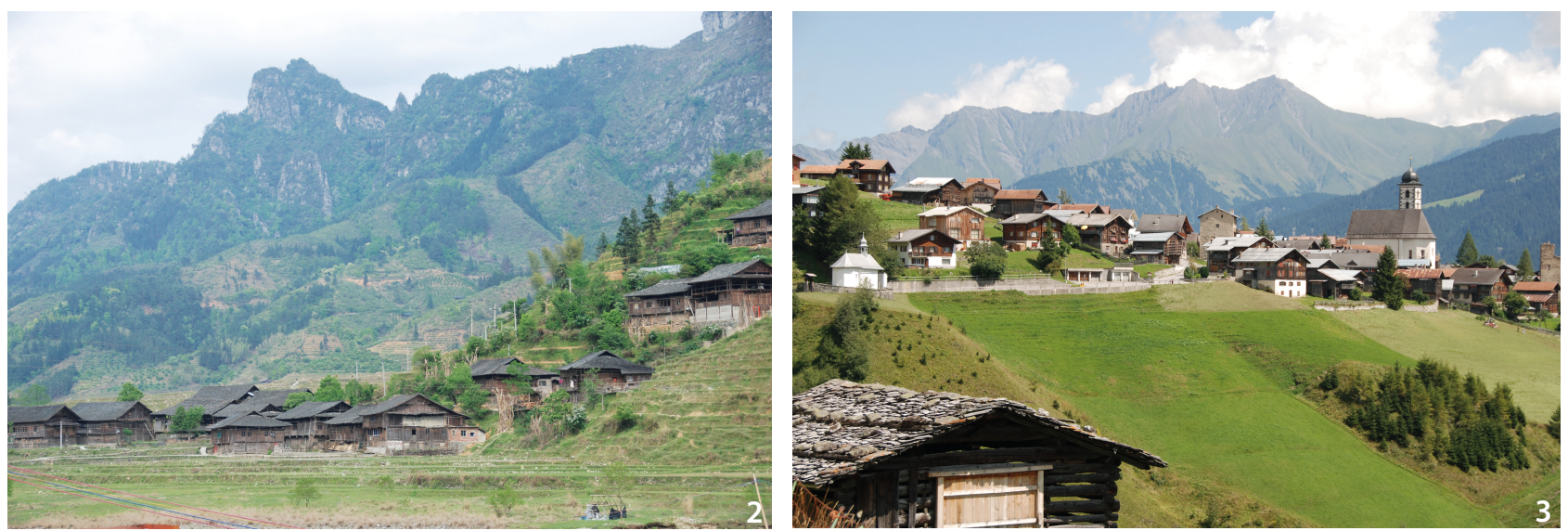

appropriate means. Different from the booming cities of China (Kunming belongs in this group), in which the development threatens to burst all seams in the shortest possible time, basic planning could be set up which could be sustainable well into the next generations and could include a regulated and logical preservation of the overall situation. The goal must be the establishment of an overall cultural landscape preservation system that attempts to guide the further socio-economic development of a region on a reasonable course which in no way hinders restrained structural improvement. Particular attention should be paid to raising the living standards of the local population in this conceptual proposal. 'Low-key' should be the catchword here, since it can hardly be the goal of a differentiated demographic development to completely eliminate the urban-rural gap. It is well known that 'modern' urban mega-cities function completely differently from the rural economical and settlement structures, developed 'harmoniously' over a long period of time, in the so-called 'underdeveloped' provinces (Figure 2).

As a Swiss monument preservationist I was reminded strongly, when confronted with the situation of the economic and planning situation I found in the provinces of Yunnan, Guizhou, Guangxi and Hunan but also Fujian which largely rural Switzerland had reached between 1950 and 1960 (before the mechanisation of agriculture and before the huge building boom following the financial boom) and which then, after 1970, resulted in the implementation of spatial planning covering the entire country of Switzerland. At that time one recognised the fact that the last remains of the historical building substance within its traditional context could only be maintained by space planning means which included preservation and further development while retaining the overall appearance. On this basis laws were created in Switzerland which since the seventies has led to an effective, governmental monument preservation system in the 26 cantons (i.e. the 26 sovereign parts of the Swiss Confederation). One of these cantons, the Canton of Grisons, undertook great political and economic efforts to make it possible for the important Albula and Bernina Railroads (built from 1898-1903/19051910) to be included in the UNESCO World Heritage list. The railroads were a pioneering achievement of the industrial and engineering art of the early $20^{\text {th }}$ century. Without the inclusion of all of the components of the singular historical cultural landscape, with wonderful old mountain villages (Figure 3) that formed the touristic arena of this stretch of railroad, these endeavour would not have been 
successful. Spatial planning and economic stimulation were of special importance. In 2008 both stretches of railroad were included in the list.

\section{Geographical Situation of the Shaxi Valleys in the Province of Yunnan}

Shaxi lies to the west in the province of Yunnan, near the Yangtze River (Tiger Leaping Gorge) in Jianchuan County (Autonomous prefecture of Dali) between Lijiang and Dali Old Town. The valley is reached by automobile along the only lane leading through a protected landscaped area. Starting from Lijiang or Dali old town the journey there is very impressive. However the fact that Shaxi Valley is indeed nearer to the touristic intersections of international and national tourisms and can easily be reached from the Lijiang and Dali airports as well as by the fully developed road and rail connections from Kunming, that for topographical reasons, it nevertheless lies off the beaten track from visitor sites of mass tourism. An ideal situation for the development of a soft tourism such as the Shaxi Rehabilitation Project, which is attempting to make a longterm development of the Shaxi Valley to be one of its most strategic pillars.

The Shaxi valley forms a broad funnel surrounded by hills, with an area of ca. $270 \mathrm{~km}^{2}$, in which a political community unit with eight villages and ca. 20,000 inhabitants live (Figure 4). The capital is Sib Denx in the inferior area of the Shaxi river valley. Shaxi lies on the old economic route from Yunnan to Tibet (Tea and Horse Caravanning Trail)(Forbes 2011).

Sib Denx itself is an old market and reshipment centre (a caravanserai for the exchange of horses) and a place where local salt trading also played an important part.

The area belongs to the culture of the Bai Minority mixed with elements of the Yi Minority.

\section{Partner in the Shaxi Project as Basis for an Exper- tise Specific Chinese-Swiss Cooperation.}

After experts from the Institute for Spatial and Landscape Development (IRL) of the Swiss Institute of Technology (ETH), who at that time worked together with the city partnership of Zurich-Kunming, were invited by the Jianchuan County Government (of the Autonomous Prefecture of Dali, in the Province of Yunnan) in the year 2000 to identify development possibilities for these administrative districts, the ETH institute initiated the 'Shaxi Rehabilitation Project' (SRP) for the socio-economic development of the Shaxi Valley in Jianchuan County (Figure 5). From the beginning, the structure of the project was based

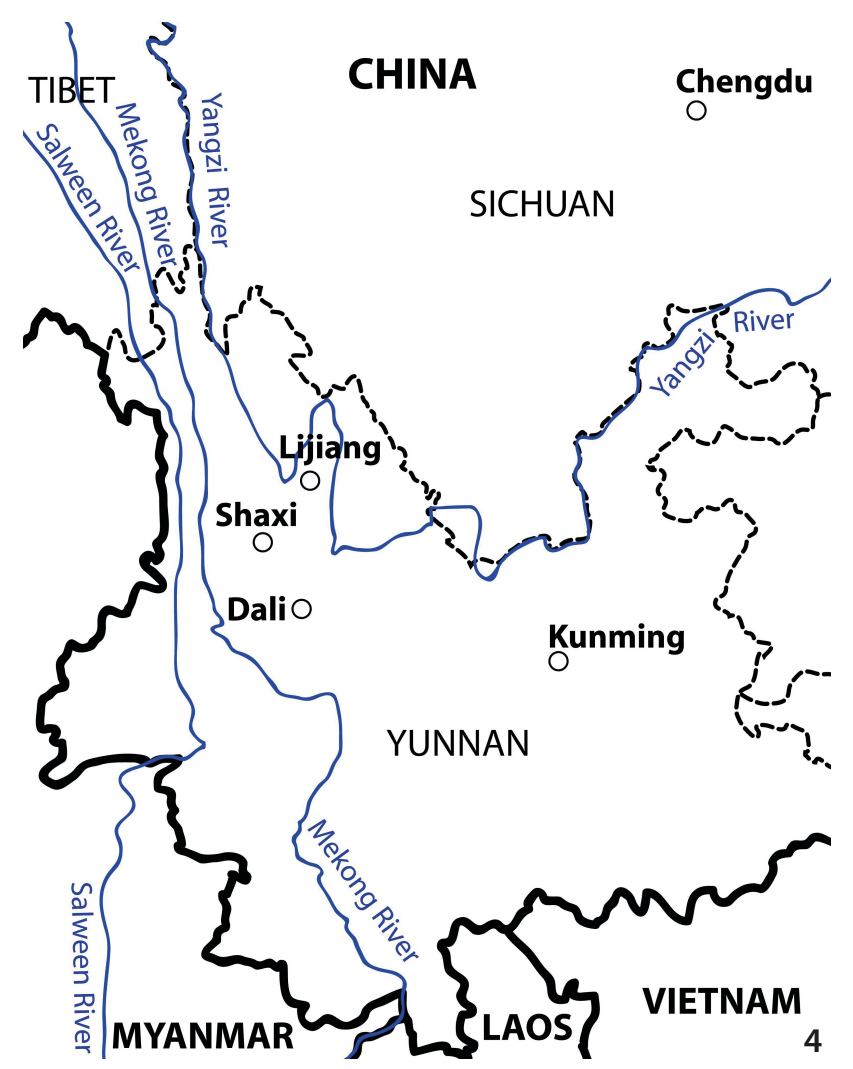

Figure 4 Yunnan-Sichuan map with location of Shaxi (Source: the author)

upon an active collaboration between the Swiss Institute of Technology and the local responsible authorities.

On the Chinese side the following took part: the authorities and planning positions of the province of Yunnan and Jianchuan County, as well as the local town government of Shaxi, supported by the ministry of Construction in Beijing. The control was by the county.

It was mutually agreed that the scientific-technical development of the project would lie in the hands of the ETH, but that the project development and scheduled execution would be carried out in close agreement of both partners, who together would be responsible for financing and execution. After a combined first development phase (2001-2004), the sole responsibility for the resulting implementation was to be transferred to the local authorities who would be able to count on the continued support of the Swiss project partners ETHZ/IRL. From 2008 on, the newly established IRL-ETHZ-Spinoff firm LEP Consultants AG (managing director Mr Diego Salmeron) took over this assignment.

The project exhibited the following goals in three phases:

Phase 1 (2001-2004): Project development and the first on-site building construction in Sib Denx, where the local building contractors could be established and the trade craftsmen could be trained in older techniques. 


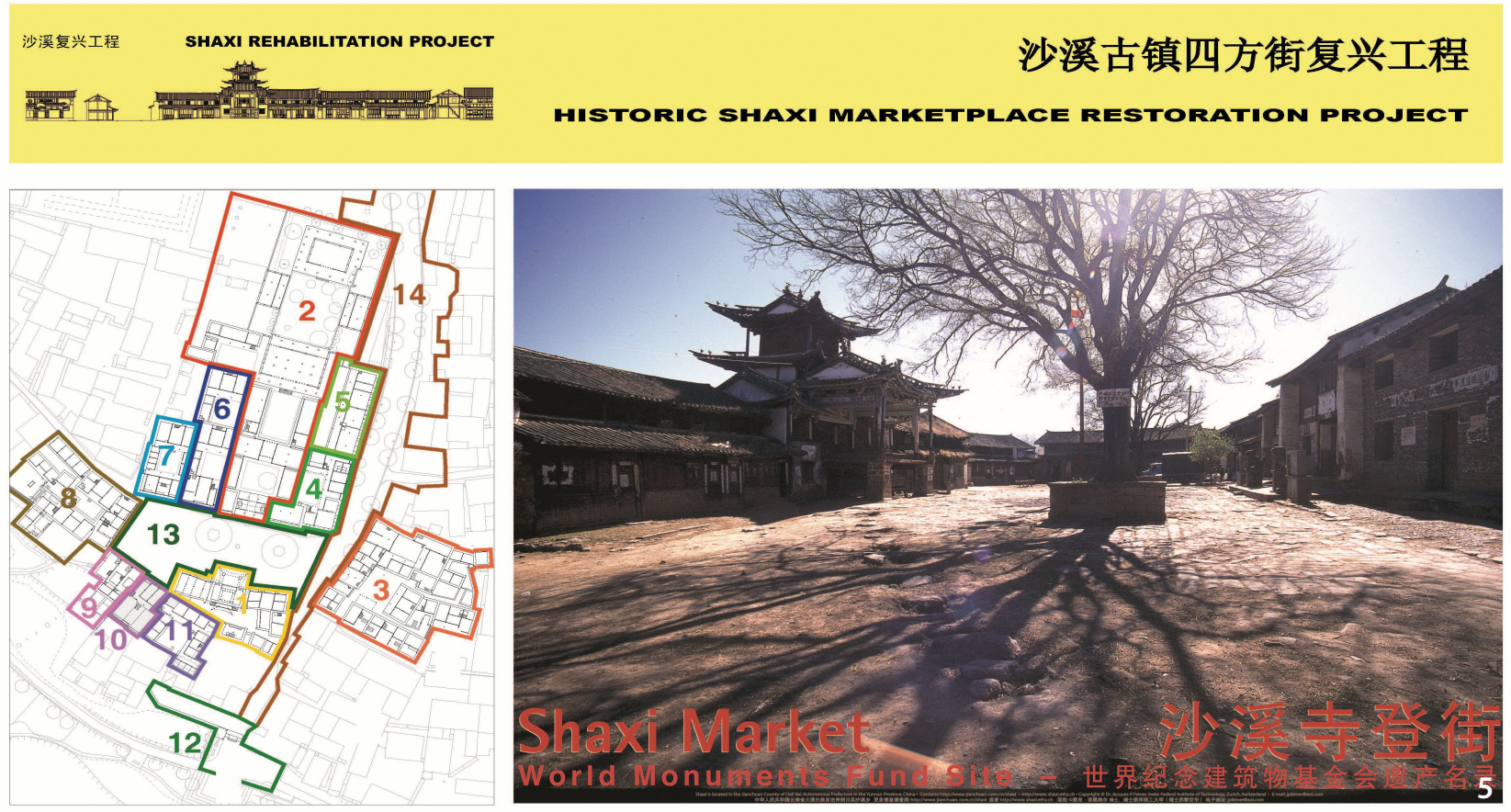

Figure 5 Historic Shaxi Marketplace restoration project and its present condition (Source: the author).

Phase 2 (2005-2006): Foundation of the Shaxi Preservation and Development Bureau under one of the local authorities (a management committee), who would take over the management and supervision of the monument preservation project on site and be in charge of the long term implementation of socioeconomic spatial planning in the Shaxi Valley.

Phase 3 (2007-2010): Restoration work, extending over many years, of the main hall of the Xingjiao Temple including the more then 500 years old mural paintings as the most important monument preservation project component, which also served as an exercise course for the training and development of Chinese restoration experts.

Development of strategies for the regional economic development of the Shaxi Valley on the basis of a status analysis together with development alternatives, with the assistance of the Swiss project partners (ETHZ/IRL/LEP). 2011 LEP was ordered by the Jianchuan County administration with the revision of the existing masterplan and the determination of the zoning plan. Now these documents are accorded and declared as an obliging basis by the local and superior authorities.

It should be mentioned here that the conceptual study for the Shaxi Rehabilitation Project was based from the beginning on a vision and cultural revaluation of the historic trade route from Yunnan to Tibet (Tea and Horse Caravan Trail) (Yang 2004), which is of enormous importance in the history of China and which in the long run, as exemplified in modern times by the reactivated Silk Route or in the style of the national renewal project for the 'Grand Canal' (Royal Canal) in the east of the country, could be of supra-regional (national) importance. For this purpose long-termed efforts and sustainable resource planning would be necessary, which could only be launched by the Chinese national authorities.

\section{Financing the Project}

In the year 2001, the Shaxi Valley was placed on the list of the 100 most endangered cultural artefacts of the world by the World Monument Endowment Fund and was promised financial support for the project. A financial division between Chinese and western partners (in Switzerland the Swiss Federal Institute of Technology with support of the Agency for Development and Cooperation, SDC, in China the Ministry of Construction of the Central Government in Beijing, the People's Government of Yunnan Province and the People's Government of Jianchuan County). Several internationally active foundations and sponsors also gave financial contributions.

\section{The Conceptual Part of the Shaxi Project}

The above overviews of the problems which were to be addressed in the project resulted in the following subsections: 1. Marketplace restoration (preservation of the building substance of the historical marketplace and 
surrounding in the centrally located Sib Denx);

2. Village preservation;

3. Sustainable valley development (the further economic development of the Shaxi Valley with agriculture and mild tourism. Preservation of the beauty of the landscape and surrounding spaces in the Shaxi Valley and a soft further development) (Figure 6);

4. Ecological sanitation (improving sanitation with ecologically compatible);

5. Poverty alleviation (taking into consideration the requirements of the population);

6. Events and dissemination (promulgation and activation of the experience, planning, and technical knowhow which was gained in this project).

\section{Goal and Potential of the Shaxi Project}

1. The Shaxi Valley should retain local agriculture as an economic resource. To implement this, agriculture area amelioration (determination of the economically most promising production areas for the future) and necessary mechanical aids.

2. The Shaxi Valley should open up a soft tourism based on culture and landscape. The approach streets to the valley which presently consist of partially paved country roads should not be upgraded (passable at a maximum for small busses). Instead, the old caravan paths should be rehabilitated. The historical monuments along the route should be included (grottos in the Shibaoshan Mountains, Sibdenx Market Place with Temple and Theater Stage, etc.).

3. The living standards of the populace should be reached through technical improvements in living conditions (basic supplies, infrastructure, value of living quarters, improvements in sanitation, etc.) and improvements in the service sector (private guest houses, bed and breakfast, arts and crafts, markets with local specialties, and public meeting areas, etc.).

\section{The Results of the Restoration of the Sib Denx Mar- ket Place in Shaxi}

Centrally located Sib Denx lies picturesquely on the main river of the valley, reached by a beautiful, arched bridge.

The settlement is revealed as a, up to the present time, largely intact and closed village with a southern entrance gate and narrow, interconnected clay houses, which are grouped around the old, picturesque square, the Market Place. Two buildings dominate the square: the Xingjiao Temple and the Theater Stage with the incorporated Kuixing Tower of Ming Dynasty. Only on the border, along a new street, are there several modern houses and a school. Many of the older houses display facade paintings and carvings.

The dominant courtyard house of the Ouyang family is striking because of its especially rich decoration and its unadulterated spatial disposition. This house should receive special monument preservation considerations.

The maintenance and revitalisation measures comprise the following work:

1. Restoration of the Xingjiao Temple from the $13^{\text {th }}$ century;

2. Restoration of the Theatre Stage and Kuixing Tower with equipment from a local museum;

3. Restoration of the paving of the square and restoration of the rain water channels;

4. Reconstruction of a dilapidated house as a test building for local building workmen;

5. Restoration of two courtyard gates with two test groups of building workmen Urban restoration of the remaining South Gate;

6. New construction of the missing West Gate from existing evidence.

The restoration and reconstruction measures were part of the first phases which was inaugurated in 2004 and ended formally when the project was handed over to the local authorities in 2006.

The Shaxi Rehabilitation Project (SRP) has received several international citations, for example from the World Monument Fund (2004) and from UNESCO in 2005 (Asia-Pacific Heritage Award for Cultural Heritage Conservation). The SRP was cited by the world organisation as setting a new technical and social benchmark for the implementation of sustainable monument preservation activities in the Dali Region of the Province of Yunnan (China) and also showing how a fundamental, forward looking concept for the development of regional communities can be implemented.

\section{Results of the Realisation of Monument Preserva- tion Project Components of SRP (2012)}

Interested visitors and experts who, like myself, have visited Shaxi Sib Denx many times since 2004 and at short intervals, were able to see, during these eight years, remarkable progress in the realisation of SRP projects. Already during the inauguration ceremony after completion of the first phase, the cultural centre, the historic market square with the two flanking main buildings, the theatre stage and entrance front of the Xingjiao Temple were ideally restored. Today the Kuixing Tower from the Qing Dynasty 

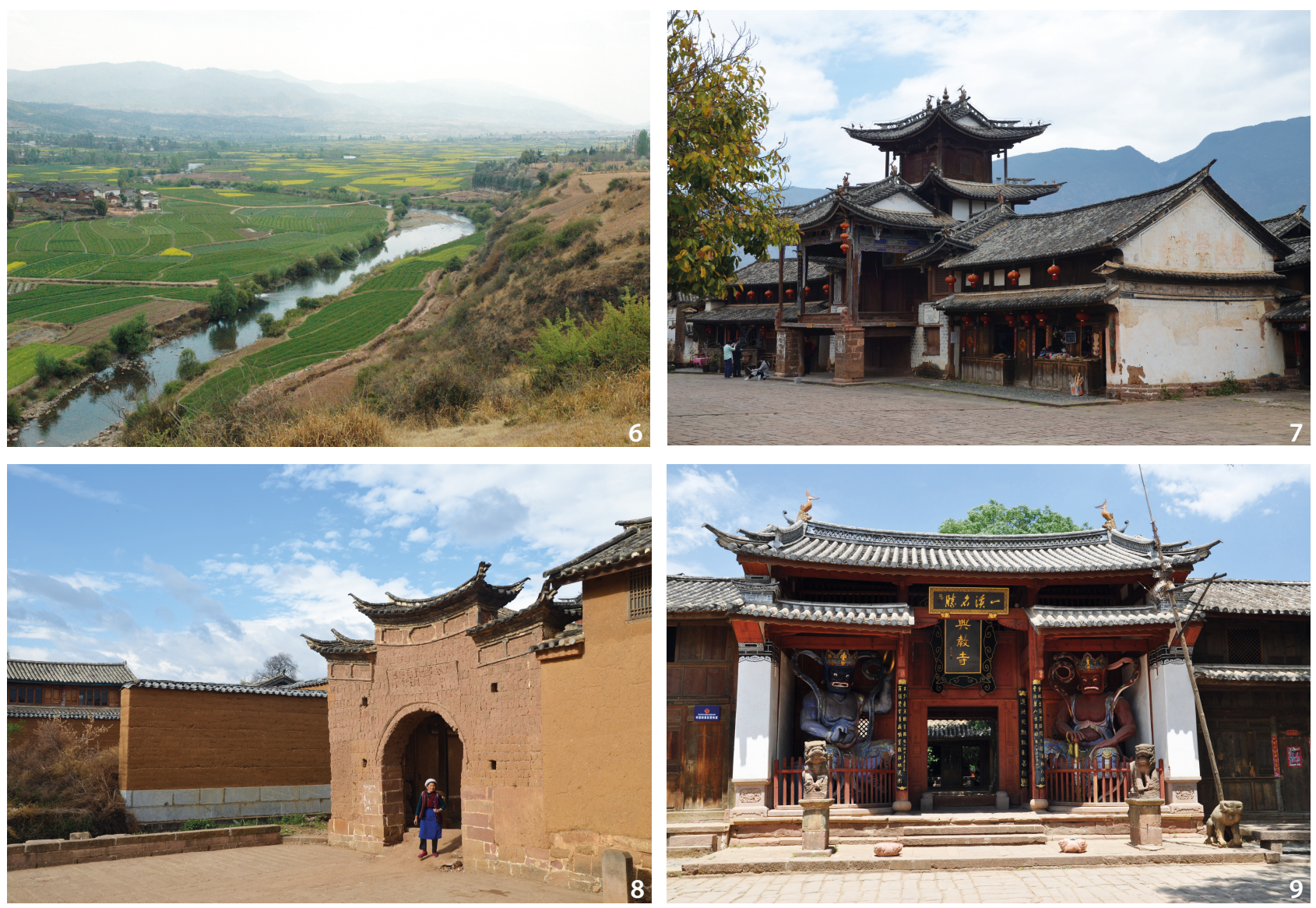

Figure 6 Historic Shaxi Valley in Yunnan (Source: the author). Figure 7 Shaxi Marketplace and theatre (Source: the author). Figure 8 Shaxi South Gate (Source: the author).

Figure 9 Shaxi Xingjiao Temple new entrance (Source: the author).

(Figure 7), which is integrated into the Theatre Stage and towers over the surrounding houses of the village, and the two City Gates, the surviving South Gate (Figure 8) and the reconstructed West Gate, form the three historic landmarks of the old marketplace of Sib Denx. In contrast to this, the 2007-2020 restored main hall of the Xingjiao Temple remains discretely hidden behind two courtyards and a high, enclosing wall.

During my short time as a guest on the project (2003), I was able to follow team discussions concerning the applicability of monument preservation principles and could see how the Chinese colleagues and administration representatives reacted to our western proposals. A specific example remains in my memory. The Chinese authorities wished, at all costs, to reconstruct the entrance front of the Xingjiao Temple in a historicized decorative style, even though there were neither documents nor pictures of this entrance situation in existence. I, myself, as a representative of Western monument preservation practices, wanted to leave the entrance as it last stood, even though this facade, facing the market place was so much changed that a visitor wouldn't imagine a temple entrance but would suspect, rather, an entrance to a private house.

The Western principle in such a case states that where no earlier condition is known it is better to retain the present one. In spite of this, I understood the Chinese method of argumentation. The temple complex that one wished to restore did not have an appropriate entrance front and therefore had no appropriate appearance of worth.

In the end the project partners agreed upon a modest compromise solution, whereby one placed on either side of the simply designed entrance two newly created guard sculptures in the traditional style (a present of Professor Willy A. Schmid, IRL/ETHZ)(Figure 9). At present a very strong, historical note is given by two ancient stone lions that historically belonged here (Huang 2009).

I had the best experiences in the Shaxi Project with the consequent use of historic building techniques and materials. Here I could observe just how carefully the existing building substance was handled and how much 
attention was paid to maintain existing assets. One didn't just replace a wooden column that was decayed at the bottom but rather a new foot was added using carpentry techniques in compliance with basic principles of monument preservation on which, especially in the west, much worth was placed, even if more often it would have been simpler to replace the complete component (Figure 10). In the building restoration, all necessary historically correct handicraft techniques that contemporary monument preservation requires came into play, such as the erection of walls with air dried clay bricks, the manufacturing of roof tiles, facade plaster work using hydraulic lime, carpentry techniques for the repair of existing wood construction, stone masonry work for foundations, plastering, historical painting techniques for the restoration of frescos in the traditional style (still existing in many houses in Shaxi) and also oil painting for the new painting of the wooden stage wing of the theatre, whose painted decorations were reconstructed in accordance with on-site findings (and a review of a later re-painting).

I regret one loss especially: a modest fresco on the stuccoed gable facade of the so-called 'Testhouse' still existed which showed a scene with a soldier of the Red Army (Figure 11). Unfortunately the façade wall sloped so much that it could no longer be stabilised in its position. It had to be broken down and redone, thus the fresco that I considered to be an extraordinary historical record was lost. If it had been a painting from the Ming Dynasty, for example, one would have made every effort to save it. However, it was not a work of art but a manifestation of a local event. Therefore one didn't even consider using the technically feasible method of removing the painted layer. This is painful for a responsible monument preservation specialist and shows that the judgment of handicraft evidences and local everyday objects should be treated more carefully. Folk art has a completely different function from high art. It arises from the cultural aspiration of the simple people who wish to make their daily life visible and thereby give expression to their personal experiences. Who painted this Red Army scene; what occasioned the painting? What did one want to express? Which heroes were meant? Was the Cultural Revolution the reason for this fresco? Who was the painter? Certainly not a trained artist but a hobby painter, perhaps one of those who created the fantastic frescoes of Bai Ethnie on the houses in Shaxi and in the outlying regions with an outstanding hand. Perhaps this lies in the essence of the foreign visitor: that his attention is turned toward such simple testimonies because for him the local cultural language is foreign and despite this he is trying to read it.

It proved successful during the execution of the work to test the construction workers on a simple object (three private courtyard entrances) and afterwards commit them to carefully maintaining original substance during the main monument protection work.

It appears to me to be indispensible that such an undertaking must be realised under the direction of an experienced monument preservationist or architect with monument protection expertise and relevant sensitivity in the handling of materials.

The lead architect Huang Yinwu, who was very familiar with both traditional Chinese architecture as well as western monument protection practices, was an exceptional find (Huang 2009). I have great respect for this engaged young monument maintenance expert whose work I could follow and who really does honour to his background in the Southeast University of Nanjing (Professor Zhu Guanya). It is to be hoped that Mr Huang will publish his experience and the methodic results of the Shaxi projects for both Chinese and western experts in a scientific publication.

\section{Personal Observations Concerning the Cultural Landscape of Southwest China.}

The Vernacular Manner of Building Construction in the Dong Ethnic Group in Guizhou and Guangxi as a Basis for a Contemporary Mode of Living Using Traditional Wooden Construction.

In the years after Shaxi (2004-2010) I undertook several personal trips to villages of the Dong and Miao minorities in the provinces of Guizhou and Guangxi.

They were mostly areas in which the prevailing construction system was of wood. The dwellings consist of a frame construction with two levels, whereby the ground floor was mostly open as shelter for animals and equipment. On the upper floor which in many ethnic groups is hardly divided, one finds the kitchen, sleeping and living areas. Such houses are of elementary construction and exhibit neither living comforts nor modern sanitation lacking any decorative applications.

These constructively very clearly conceived wood framed buildings can be extremely well modernised, in my opinion. Their construction framework-this one sees in the construction of new houses using traditional construction methods (Figure 12)-uses the same principle as the urban steel skeleton construction of modern buildings and is most suitable for flexible and changeable 

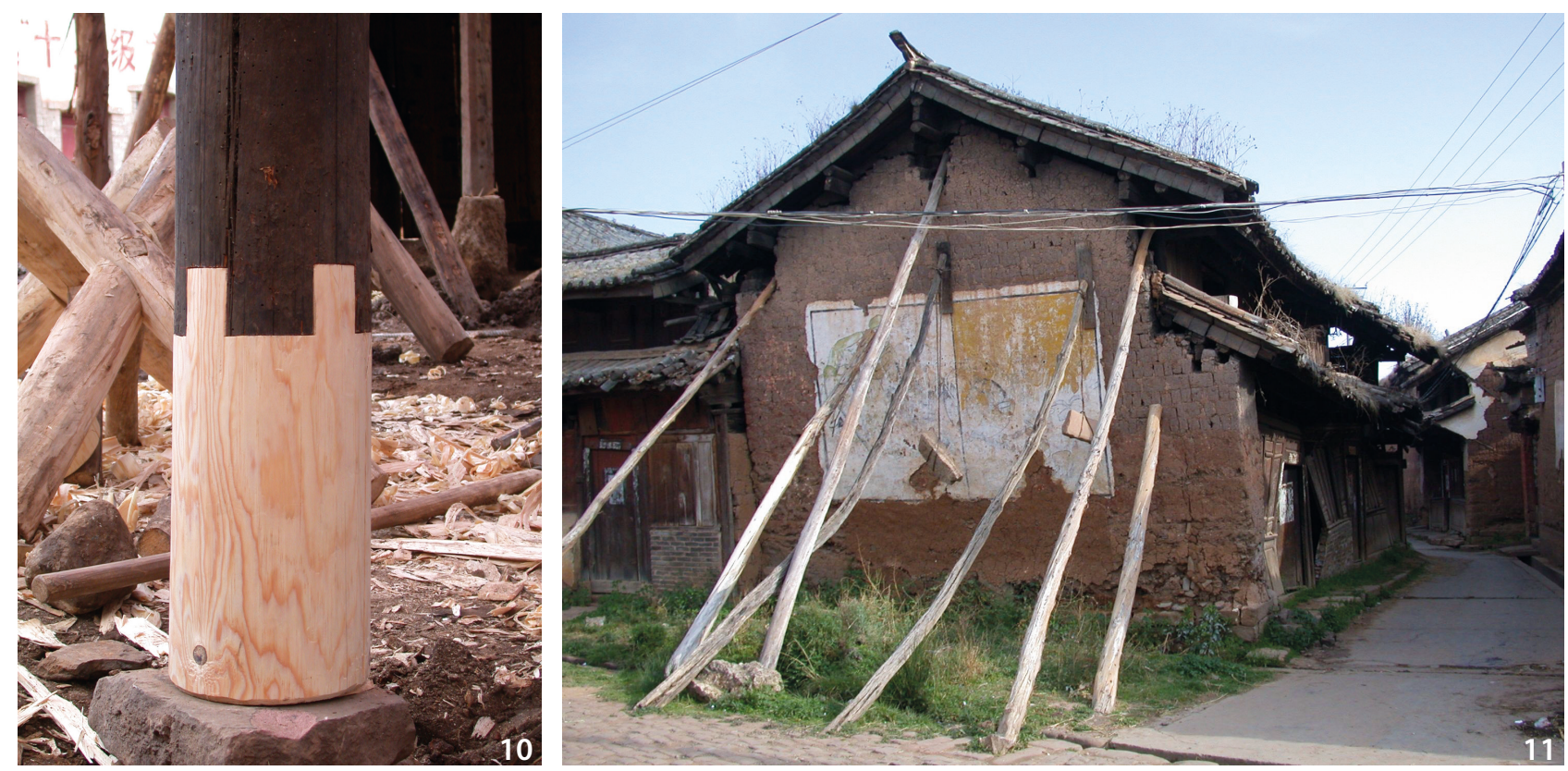

Figure 10 Example of wooden pillar restoration in Shaxi (Source: the author).

Figure 11 Portrait of Red Army on the wall of old building called 'Test building" by local people (Source: the author).

floor plans-also dwelling floor plans. They are usually of a very sturdy construction and could be improved and extended using the same construction principles. With the installation of space cells individual rooms and designated functions, such as kitchens and wet rooms (baths, showers, and toilets) could be created. Some rooms could be used as guest rooms or tourist apartments as a support for service costs. It is readily apparent to the foreigner that the intact villages lie in extremely attractive, natural surroundings, just as they were laid out centuries ago. This is touristic capital which should be used to the advantage of the local inhabitants.

\section{Rural Development and Preservation of Cultural Landscape in Southwest China}

In the eyes of western visitors, the living style of the rural Chinese population appear to be very modest. Urban modernisation hasn't reached this area and one could consider this to be a progressive chance if one doesn't immediately compare the living standards of the rural inhabitant with those of the 'modern' city dweller and thereby judge country living to be hopelessly backward. If one assumes that it would be impossible to bring city and rural living either socially or functionally under a common denominator and that any tendency for equalisation would be doomed to failure. If one is of the opinion that rural and city living cannot be brought under a common denominator either socially or functionally and that any attempt at equalisation is doomed to failure, a socio-economic concept must be found and put into practice for the country dweller that is specific to the region and suitable to the living style and can stop the obsolescent aging and population drain in the villages and can create an acceptable economic basis for the rural population. In its analysis of the local situation in the Shaxi Valley and based upon this, the ensuing revitalisation concepts for the various restructure levels (see chapters 3.5 and 3.6 above), the Shaxi Rehabilitation Project has performed a fundamental contribution and during the first decade of its implementation has produced visible results. In the long run, the sustainability of the project lies, in my opinion, entirely in the hands of a successful development management and the responsibility of the local authorities. A certain scepticism prevails not only among the western visitors, as to whether this attractive area, like so many tourist destinations in China, sooner or later will succumb to the pressures of mass tourism and the associated 'money drive' of speculative investors. At the moment, the term 'measured development' would still be appropriate to a large extent.

It is apparent to foreigners visiting rural areas of China that the intact villages often are located in beautiful, natural areas, largely as they were laid out many centuries ago (Figure 13). This is cultural capital that the local inhabitants can use. 'Soft Tourism' could be the catchword here. Soft tourism will remain only a catchword if there are no underlying clear functions and development strategies. The effort of all parties, inhabitants as well as authorities, 

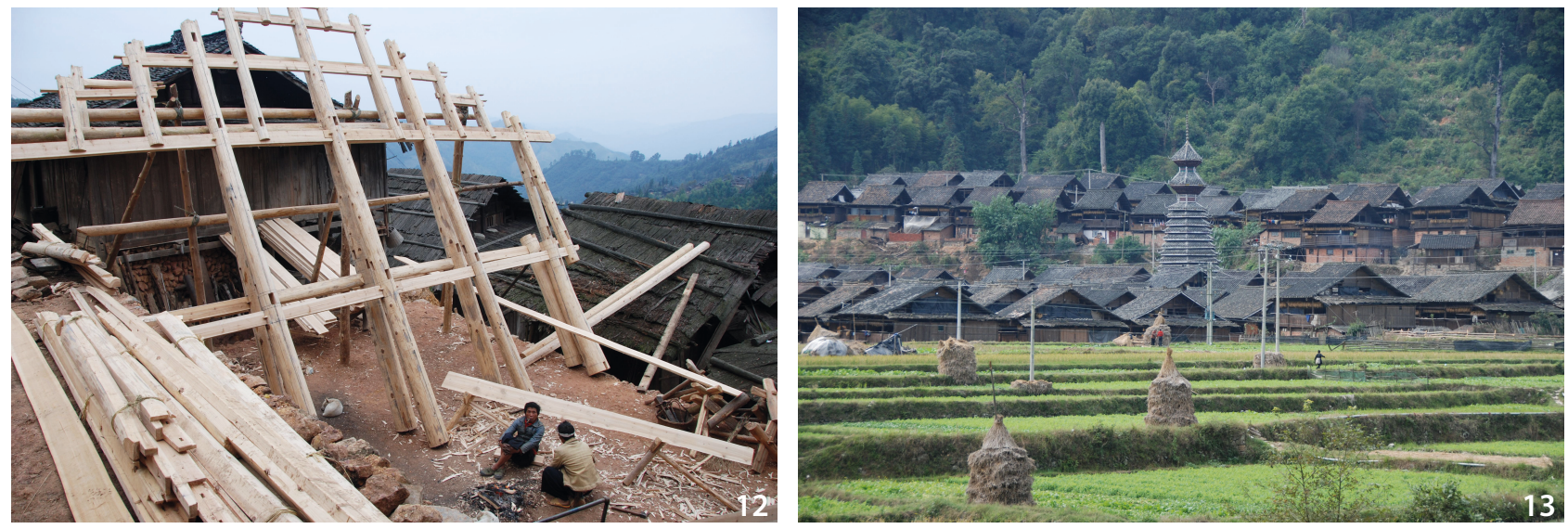

Figure 12 Wooden skeletons made by craftsmen in traditional Basha way (Source: the author). Figure 13 Dong village in Congjiang, Guizhou Province (Source: the author).

must be employed here. Before this, analyses, concepts, calculation models, as well as functioning implementation mechanisms must be set in place, which can only be initiated and realised by the authorities with the inclusion of experts such as sociologists, economists, and spatial planners.

Along with this, schooling and educational programs are required through which clarification work can be carried out and the acceptance of the local authorities and the relevant inhabitants can be reached and investors motivated. However it should be noted that these traditional settlements can only remain authentic as long as the existing traditional infrastructure, for example the fields and rice terraces, the path systems and their texture (stone slabs), the vegetable gardens and their enclosures (woven wood), the water ways (brooks and ponds) and their free courses remain intact.

These rural villages are still very far away from the great population centres. However even now the first encroachments are appearing through arbitrary and ruthless modernisation.

In the villages which I visited there is a much greater discrepancy between village dwellings and modern city habitation. Clearly, people striving to obtain new living comforts are of the view that the old houses cannot be converted to present day living standards. In addition, the economic powers of the individual families are not sufficient to enable them to take building measures which would bring an increased living comfort. They attempt to obtain new dwellings wherever possible. This is, socially seen, legitimate and of course an important political premise. However in the villages of the Dong when one sees how traditional collective works function, even in building construction, and how the required craftsmanship for traditional carpentry still exists and is successfully used in the traditional way, one recognises immediately that here a cultural potential exists that one could further develop in future for the benefit of the local inhabitants, for example in soft tourism (Figure 14). The meaningful application of the traditional skills of the local inhabitants could definitely be used to raise rural living standards and could be developed into a genuine cultural attitude. The SinoNorwegian community project in Suoga (Guizhou) and the Shaxi Rehabilitation Project in Yunnan are useful test projects for the development of the traditional cultural landscapes in rural China.

\section{The Effort from China's Side}

Chinese experts have recognised the problems and chances of the comprehensive preservation of the cultural landscape. In the spring of 2011 a group of scientists under the chairmanship of Professor Zhu Guanya (SEU) prepared a paper entitled: 'Expert agreement concerning "Research Report on the Protection and Development Plan of Minority Villages" - 2011-04-22', in which the problems were analysed and approaches to problem solutions were presented. One speaks of 3000 villages requiring protection in the areas of national minorities, which should be included in the investigation during the next five years. Currently the paper lies with the appropriate ministry in Beijing. One is curious about the manner in which this ambitious undertaking will be implemented.

In the rural area there are not enough funds to build new dwellings on a grand scale conforming to social requirements. Apart from the legitimate question of general prosperity, a great opportunity for the conservation of traditional cultural values is available in all rural provinces 


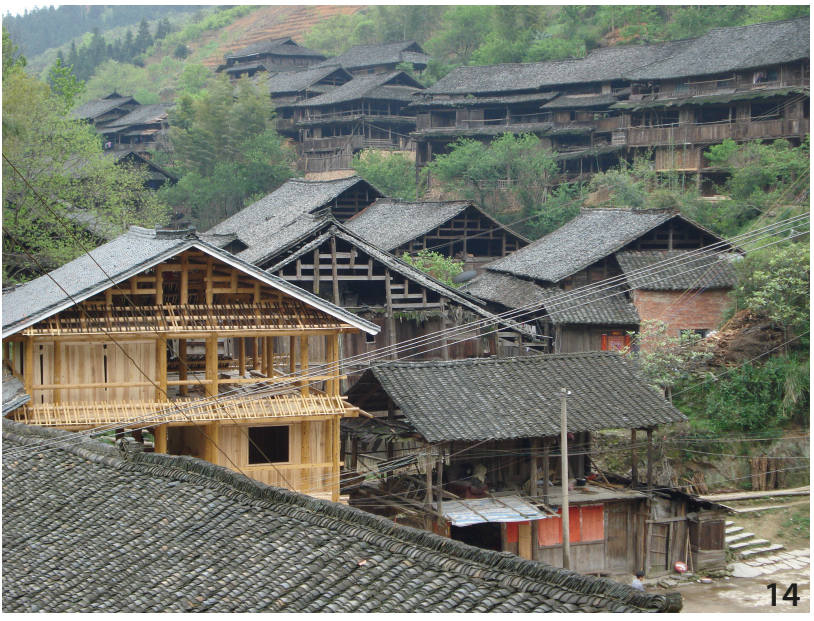

Figure 14 New residents built in traditional wood craft in Dong village in Chengyang, Guangxi (Source: the author).

of the Southwest, which in other areas of China have long been forfeited. A reckless touristic marketing would be extremely damaging to this culture. These regions must be developed with other means.

The basic prerequisites for the conservation of the traditional building culture is functioning spatial planning, within which legal parameters for monument protection can be implemented. Counselling of the population in questions of monument preservation should be performed by trained architects and construction experts. A prerequisite there would be specialist training in monument preservation and the history of architecture. The training could be offered in such special courses in the best universities of China. At Tongji University in Shanghai last year the essential step was done with the realisation of a master study in monument preservation in 2012.

\section{Conclusions Reached after the Last Visit to the Shaxi-Valley in the Fall of 2016}

Because of its uniqueness, the 'Shaxi Rehabilitation Project' has acquired very much attention. Countless Chinese and foreign delegations have visited Shaxi in the last 1015 years and the project has been highly regarded.

Diego Salmerón, the former Project Manager of the Shaxi Rehabilitation Project and at present consultant to the local administration, has also, through his firm LEP Consultants, been advising planning administrations throughout the whole of China since 2008 in their projects for future city development and technical supports as well as procedural processes.

In the two decades since its completion the further development in Shaxi Valley and its central market place
Shaxi Old Town (Sideng) has been judged quite positively. In addition to the successful components, the well known results of an ascending stream of tourists has been observed. Not only quiet Guest Houses are in demand but also consumer goods, souvenir shops, and bars.

Essential for the development of Shaxi Valley is the fact that although it is in the sphere of influence of touristic nodal points of international and national tourism such as Lijang and Dali, for topographical reasons, it lies off the beaten track of the well-known sites of mass tourism. An ideal basis for the development of a responsible concept of tourism, as was the basis of the Shaxi Rehabilitation Project from the beginning.

\section{References}

Forbes, Andrew and Henley David. 2011. China's Ancient Tea Horse Road, Chiang Mai: Cognoscenti Books.

Huang, YW. 2009. Reading Time in Shaxi, Kunming: Yunnan Nationalities Publishing House.

Lehner Erich and Harrer, A. S., Hildegard. 2010. Along the Great Wall: Architecture and Identity in China and Mongolia, Institute for Comparative Research in Architecture, Vienna: Vienna TU.

Yang, Fuquan 2004. "The 'Ancient Tea and Horse Caravan Road' - The 'Silk Road' of Southwest China”. The Silkroad Foundation Newsletter 2 (1). Accessed March 1 2013. http://www.silkroadfoundation.org/ newsletter/2004vol2num1/tea.htm 